\title{
Structure of MgO Films Prepared by Ion Beam Sputtering
}

\author{
Tsuguo ISHIHARA and Muneyuki MOTOYAMA \\ (Industrial Research Institute of Hyogo Prefecture, 3-1-12, Yukihira-cho, Suma-ku, Kobe-shi \\ イオンビームスパッタリングにより作製した $\mathrm{MgO}$ 膜の構造
}

石原嗣生・元山宗之

(兵庫県立工業試験場，654 神戸市須磨区行平町 3-1-12)

\begin{abstract}
Preferred orientation and microstructure of $\mathrm{MgO}$ films prepared by ion beam sputtering were investigated. The crystallographic orientation of $\mathrm{MgO}$ films was a function of the substrate angle $(\delta), O_{2}$ gas partial pressure $\left(P_{o_{2}}\right)$ and the substrate temperature $\left(T_{s}\right)$. As $\delta$ changed from $90^{\circ}$ to $0^{\circ}$, the transmission electron diffraction (TED) pattern of the films deposited in $P_{o_{2}}$ of $1 \times 10^{-4}$ Torr at $T_{s}=R . T$. changed from a random orientation to the (111) preferred orientation in which the crystallographic (111) plane was parallel to the substrate surface. An increase in $P_{o_{2}}$ from $0.1 \times 10^{-4}$ to $10 \times 10^{-4}$ Torr caused the (111) preferred orientation. At $T_{s}>100^{\circ} \mathrm{C}$, the TED pattern of the films on $\mathrm{NaCl}$ (200) deposited with $\delta=90^{\circ}$ showed epitaxial growth in contrast with a random orientation at $T_{s}<100^{\circ} \mathrm{C}$. Annealing below $500^{\circ} \mathrm{C}$ did not change the orientation and size of the crystallite. Annealing above $1000^{\circ} \mathrm{C}$ for $30 \mathrm{~min}$, however, caused crystallite growth from $5 \mathrm{~nm}$ to $20 \mathrm{~nm}$ without any change in orientation. This size is still smaller than that of the crystallites deposited on a heated substrate. The origin of the crystallographic preferred orientation of the $\mathrm{MgO}$ thin film deposited by ion beam sputtering was explained in terms of the growth competition. The (111) preferred orientation becomes predominant in the growth competition over others with decreasing the arrival ratio of $\mathrm{Mg} / \mathrm{O}$.

[Received August 20, 1988; Accepted May 16, 1989]
\end{abstract}

Key-words : MgO film, Preferred orientation, Microstructure, Ion beam sputtering

\section{Introduction}

$\mathrm{MgO}$ film has recently been investigated ${ }^{1-9)}$ with special attention to the excellent high temperature chemical stability, electrical insulating property, optical property and thermal conductance. Many electron and X-ray diffraction investigations have shown that the crystal orientation of vapor deposited $\mathrm{MgO}$ films depends on deposition process.

Chemical vapor deposition (CVD) processes ${ }^{11}$ have been developed using organometallic compounds for depositing $\mathrm{MgO}$. The crystallite of $\mathrm{MgO}$ films deposited at $310^{\circ} \mathrm{C}$ or above by $\mathrm{CVD}$ was found to possess a (200) preferred orientation in which the crystallographic (200) plane is parallel to the substrate surface.

The crystal orientation of $\mathrm{MgO}$ films by thermal evaporation onto amorphous and single crystal substrates varied with film thickness. According to the studies by Aboelfotoh et al. on amorphous substrates, the $\mathrm{MgO}$ films initially nucleate in a random orientation. As the film thickness increases, a (111) preferred orientation develops on the surface. ${ }^{2), 31,5)}$ On single crystal substrates, the orientation of crystallite in thin films (below $3 \mathrm{~nm}$ ) depends on the crystal face and temperature of the substrates. In the range of thickness from 3 to $50 \mathrm{~nm}$, the crystallite tends to orient randomly, and in thick films (above $50 \mathrm{~nm}$ ) the surface structure has a (111) preferred orientation independent of the substrate orientation and temperature. ${ }^{4,6)}$

$\mathrm{MgO}$ film formed by rf-sputtering of $\mathrm{MgO}$ target was found to have a strong tendency to form a columnar structure of the (200) orientation normal to the substrate. However, by decreasing the sputtering pressure less oriented coatings of denser structure can be obtained at a moderate temperature. ${ }^{7,8)}$

Reactive ion beam sputter deposition (RIBSD) method $^{9)}$ using a magnesium target was found te produce smooth $\mathrm{MgO}$ film dielectrics with low electrical loss, good mechanical stability, and excellent reproducibility. ${ }^{9)}$ This technique has received attention with respect to the low temperature production of ceramic thin films for recent ten years. However, microstructure and preferred orientation of the $\mathrm{MgO}$ film deposited by RIBSD have not been investigated yet, although these are the important aspects of the thin film.

In this study, we report on the influence of preparation conditions of $\mathrm{MgO}$ films on the crystallographic orientation and on the microstructure of the film in comparison with the previously reported results. 


\section{Experimental}

$\mathrm{MgO}$ films were prepared by a Koon Denki ion beam sputtering apparatus. The apparatus and preparation condition were described in Fig. 1 and Table 1. The magnesium target was a metallic disk of $4 \mathrm{~N}$ grade with $100 \mathrm{~mm}$ diameter and $5 \mathrm{~mm}$ thickness. Argon ion beam generated in a Kaufman-type ion gun was accelerated to $4-5 \mathrm{kV}$ energy with 10-12 $\mathrm{mA}$ current and sputtered the target at an incident angle of $30^{\circ}$. The target was located at a distance of $200 \mathrm{~mm}$ from the acceleration grids of the $40 \mathrm{~mm}$-diameter ion source. An aluminum plate with a $40 \mathrm{~mm}$-diameter hole was placed between the ion gun and the target to

Table 1. Deposition conditions.

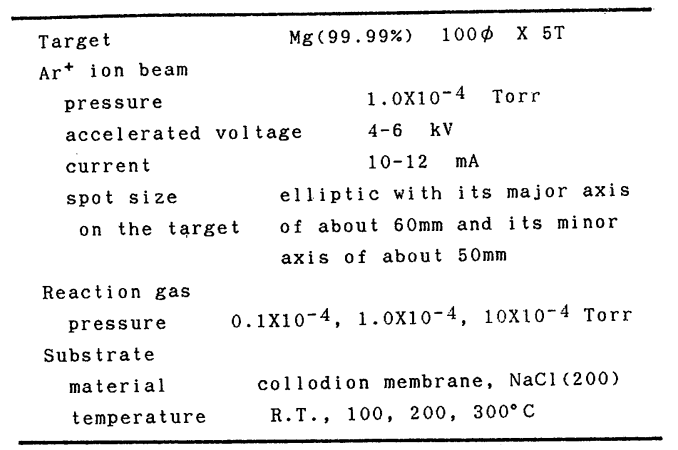

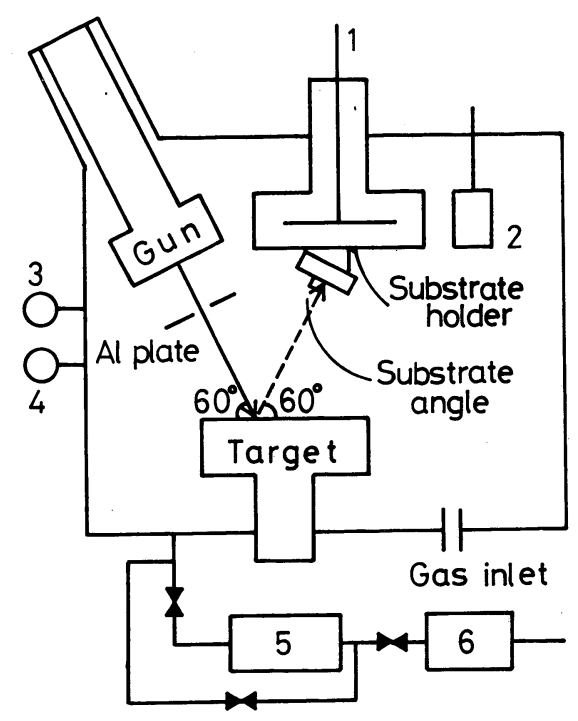

Fig. 1. Schematic diagram of the ion beam sputtering apparatus and relationship between $\delta$ and incident ion beam. 1 : substrate heater $; 2:$ thickness monitor; 3 : Pirani gauge ; $4:$ Penning's gauge ; 5 : molecular turbo pump $; 6:$ rotary pump reduce the ion beam spread. The ion beam spot on the target was elliptic with its major axis of about $60 \mathrm{~mm}$ and its minor axis of about $50 \mathrm{~mm}$. The sputtering chamber was once evacuated to a pressure of $2 \times 10^{-6}$ Torr, and then argon gas was introduced to a pressure of $1 \times 10^{-4}$ Torr. During the deposition, oxygen gas was also introduced to the partial pressure $\left(P_{\mathrm{O}_{2}}\right)$ between $0.1 \times 10^{-4}-10 \times$ $10^{-4}$ Torr. The resulting deposition rates were $0.05-0.3 \mathrm{~nm} / \mathrm{min}$. Film thickness was determined from crystal quartz thickness monitor readings. The thickness was $20-30 \mathrm{~nm}$. The substrates used were collodion membrane on a $\mathrm{Pt}$ mesh and cleaved single crystal $\mathrm{NaCl}(200)$. The substrates were placed at an angle of $30^{\circ}$ from the target normal and on the incident plane of the ion beam. The incident angles of sputtered particles measured from the substrate surface (or the substrate angle $\delta$ ) were chosen to be $0^{\circ}, 60^{\circ}$ and $90^{\circ}$. In Fig. $1, \delta$ is illustrated to be $90^{\circ}$. The distance between the target and the substrate was adjusted to be $50-70 \mathrm{~mm}$. The substrate temperature $\left(T_{\mathrm{s}}\right)$ during film deposition was set at a room temperature (R. T. ), $100^{\circ}, 200^{\circ}$ and $300^{\circ} \mathrm{C}$. The microstructure and the crystallographic orientation of the $\mathrm{MgO}$ film were examined by an analytical electron microscope (JEOL 2000 FX). Possible impurities in the $\mathrm{MgO}$ films originated from the ion source, the aluminum plate and the other part of the apparatus such as the target holder were not detected by EDX detector. The reason why the impurities originated from the ion source were not detected is because of the use of a carbon electrode for a rf-electrode and an acceleration electrode. ${ }^{10)}$ The reason why the impurities originated from the hole edge of the aluminum plate were not detected is probably because of the low sputtering yield of an aluminum atom by an argon ion beam and the low current density of an argon ion near the aluminum hole edge.

\section{Results}

\subsection{The effect of substrate angle on the diffraction patterns}

Figure 2 shows the transmission electron diffraction (TED) patterns of films deposited on collodion membrane at $T_{\mathrm{s}}=\mathrm{R} . \mathrm{T} ., \quad P_{\mathrm{O}_{2}}=1.0 \times$ $10^{-4}$ Torr and each $\delta$. All the diffraction patterns were not spots but continuous rings, indicating that the films consist of fine crystals. It is clear from these diffraction patterns that the crystallite orientation changes with $\delta$. At $\delta=0^{\circ}$ the TED pattern (Fig. 2(a)) showed a strong (220) diffraction ring and weak (111) and (200) diffraction rings. At $\delta=60^{\circ}$ the relative intensity of the (111) and (200) diffraction rings (Fig. 2(b)) became 

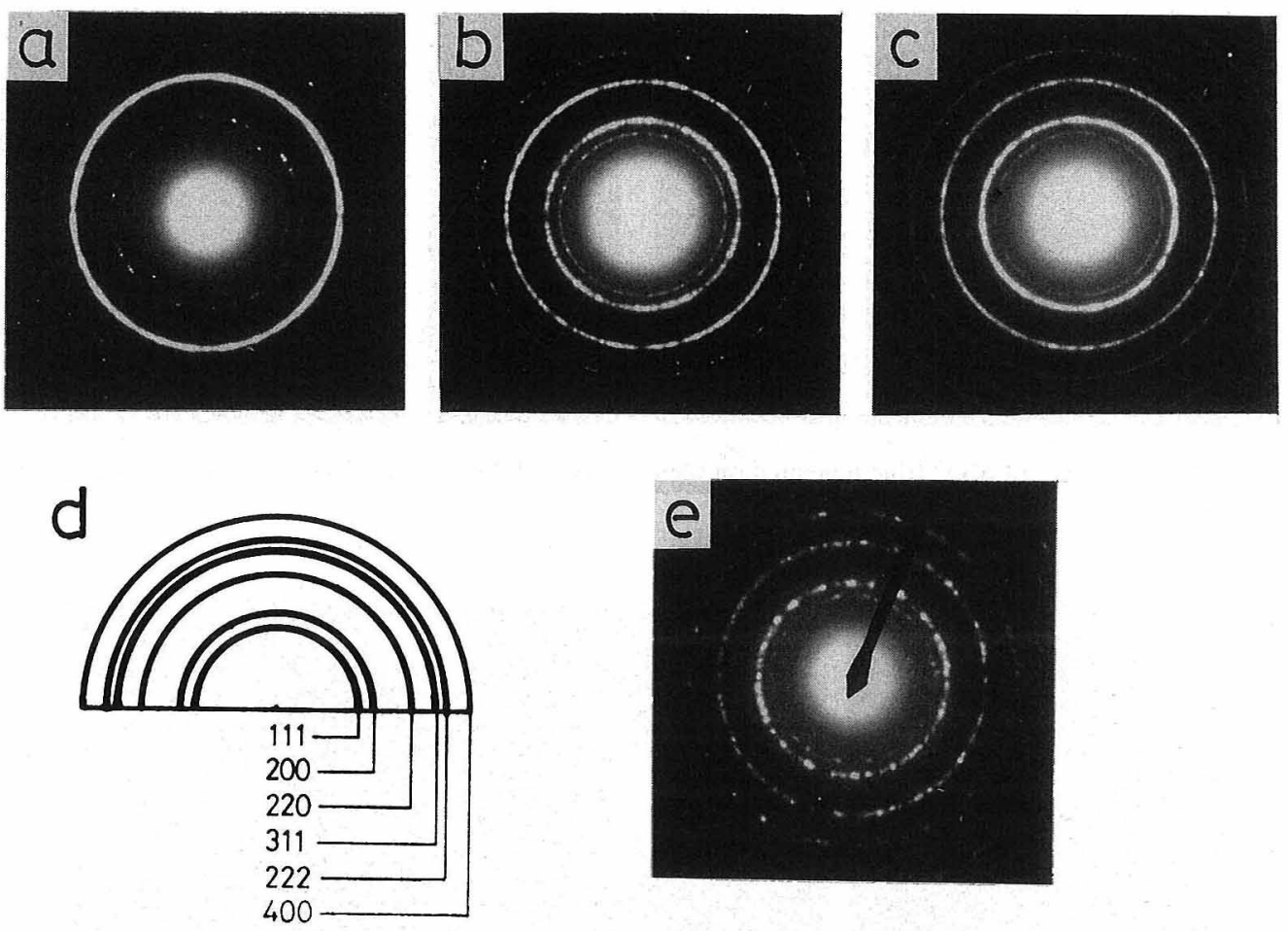

Fig. 2. TED patterns of $\mathrm{MgO}$ film deposited on collodion membrane at $T_{\mathrm{s}}=\mathrm{R}$. T., $P_{\mathrm{O}_{2}}=1.0 \times 10^{-4} \mathrm{Torr}$ and $\delta$ (a) $0^{\circ}$, (b) $60^{\circ}$ and (c) $90^{\circ}$, (d) schematic representation of the diffraction pattern, (e) TED pattern of $\mathrm{MgO}$ fine powder.

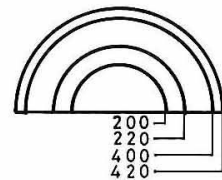

$\left(\begin{array}{lll}1 & 0 & 0\end{array}\right)$

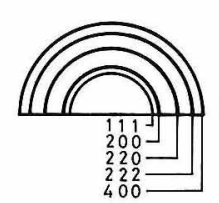

$\left(\begin{array}{lll}1 & 1 & 0\end{array}\right)$

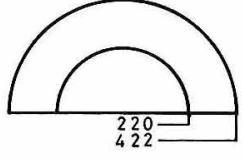

$\left(\begin{array}{lll}1 & 1 & 1\end{array}\right)$
Fig. 3. The relationship between TED patterns and preferred orientations in the case of face-centered cubic lattice.

stronger than in Fig. 2(a). At $\delta=90^{\circ}$ the relative intensity of the diffraction rings (Fig. 2(c)) approached those of the random orientation such as $\mathrm{MgO}$ fine powder as shown in Fig. 2(e). Figure 3 shows the relationship between TED patterns and preferred orientations in the case of the face-centered cubic lattice. From Fig. 3 the $\mathrm{MgO}$ film of the TED pattern (Fig. 2(a)) is known to possess a (111) preferred orientation. On a cleaved $\mathrm{NaCl}$ (200) substrate, the TED patterns showed the same tendency. Therefore, the crystallographic orientation at $T_{\mathrm{s}}=\mathrm{R}$. T. is not affected by substrates.

\subsection{The effect of $\mathrm{O}_{2}$ gas partial pressure on the diffraction patterns}

Figure 4 shows TED patterns of films deposited on collodion membrane at $\delta=60^{\circ}, T_{\mathrm{s}}=\mathrm{R}$. T. and each $P_{\mathrm{O}_{2}}$. At $P_{\mathrm{O}_{2}}=0.1 \times 10^{-4}$ Torr the TED pattern (Fig. 4(a)) showed diffraction rings assigned to a random orientation. On the other hand, in the TED pattern (Fig. 4(b)) of the film deposited at $P_{\mathrm{O}_{2}}=1.0 \times 10^{-4}$ Torr, the relative intensity of the (200) diffraction ring decreased, while that of the (220) diffraction ring increased. Further, at $P_{0_{2}}$ $=10 \times 10^{-4}$ Torr, only the $(220)$ diffraction ring was observed. These results suggest that as $P_{0_{2}}$ increases, the TED pattern changes from a random orientation to the (111) preferred orientation.

\subsection{The effect of substrate temperature on the diffraction patterns}

Figure 5 shows the TED patterns of films deposited on a cleaved $\mathrm{NaCl}$ (200) surface at $\delta=$ $60^{\circ}, P_{\mathrm{O}_{2}}=1.0 \times 10^{-4}$ Torr and each $T_{\mathrm{S}}$. At $T_{\mathrm{S}}=$ $\mathrm{R}$. T. the TED pattern showed only diffraction rings assigned to a random orientation of crystallite as mentioned before. The TED pattern changed with increase in $T_{\mathrm{s}}$. At $T_{\mathrm{S}}=100^{\circ} \mathrm{C}$ the TED pattern showed both diffraction rings and spots. And then at $T_{\mathrm{S}}=200^{\circ} \mathrm{C}$, the TED pattern 

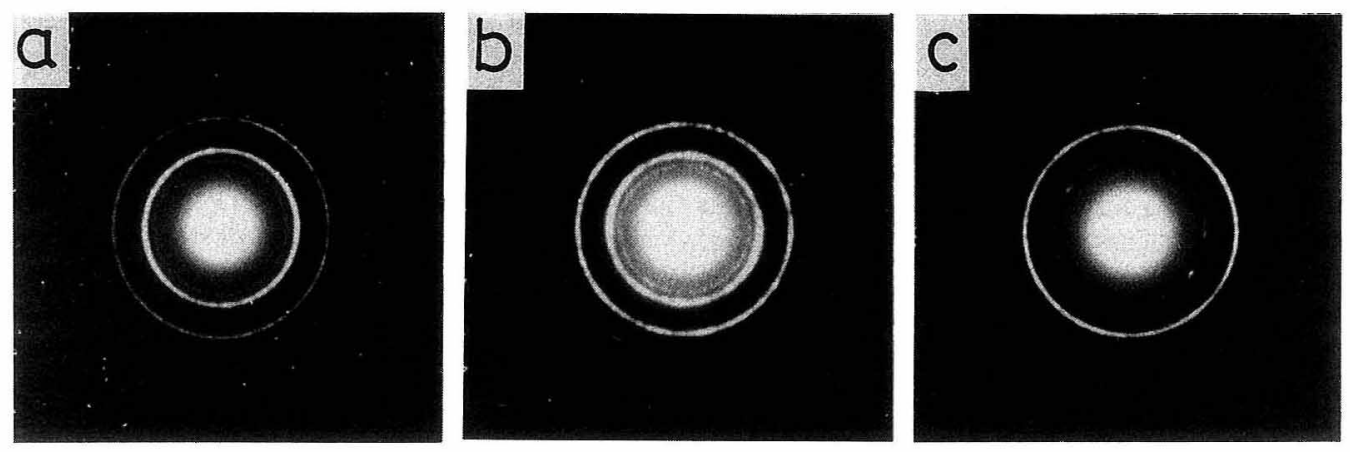

Fig. 4. TED patterns of $\mathrm{MgO}$ film deposited on collodion membrane at $T_{\mathrm{s}}=\mathrm{R}$. T., $\delta=60^{\circ}$ and $P_{\mathrm{O}_{2}}$ (a) $0.1 \times$ $10^{-4}$, (b) $1.0 \times 10^{-4}$ and (c) $10 \times 10^{-4}$ Torr.
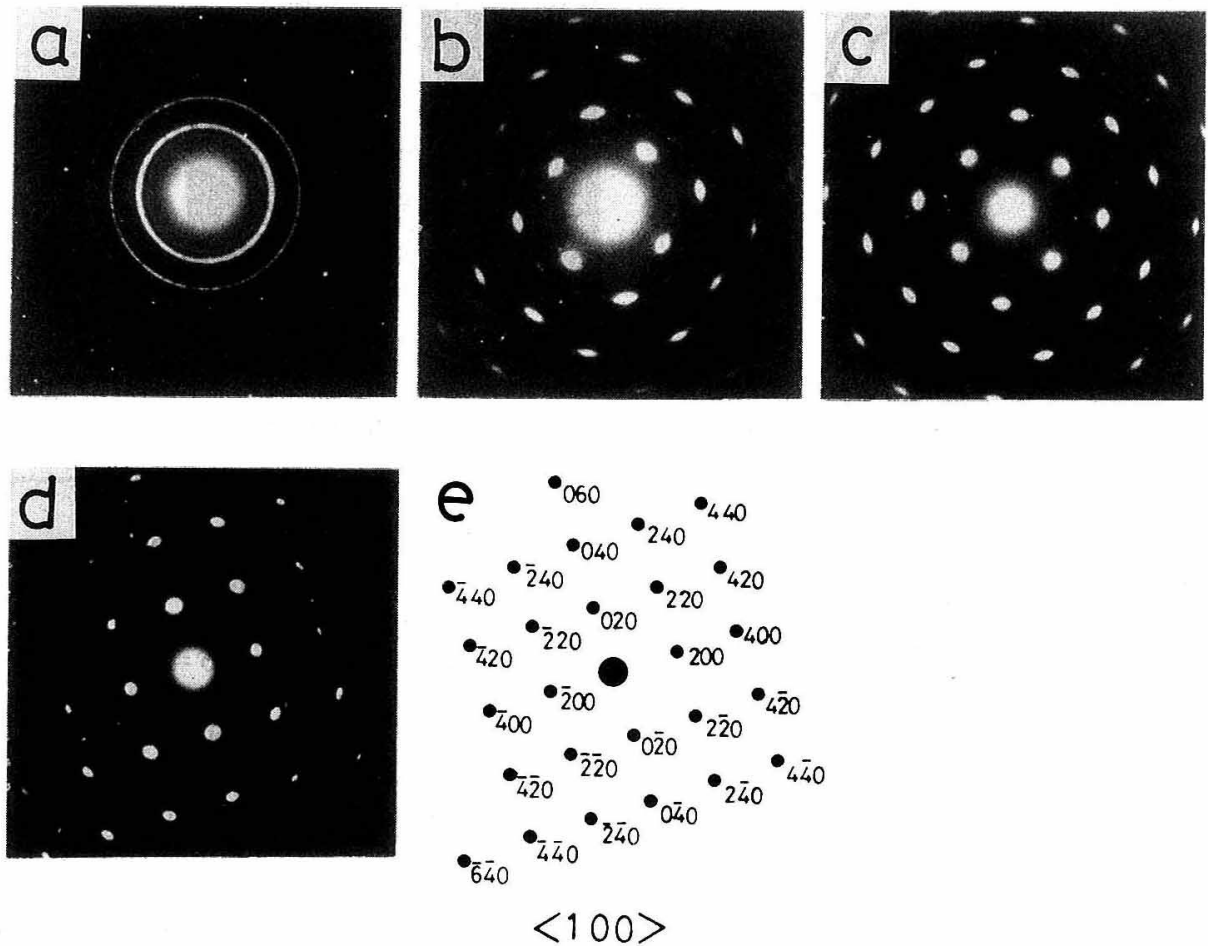

Fig. 5. TED patterns of $\mathrm{MgO}$ film deposited on $\mathrm{NaCl}(200)$ at $\delta=60^{\circ}, P_{0_{2}}=1.0 \times 10^{-4}$ Torr and $T_{\mathrm{s}}$ (a) R. T., (b) $100^{\circ} \mathrm{C}$, (c) $200^{\circ} \mathrm{C}$ and (d) $300^{\circ} \mathrm{C}$, (e) interpretation of the diffraction pattern (d).

showed the diminution of diffraction rings, and further at $T_{\mathrm{s}}=300^{\circ} \mathrm{C}$ it showed only diffraction spots. The TED pattern (Fig. $5(\mathrm{~d})$ ) shows epitaxial growth of $\mathrm{MgO}$ films on $\mathrm{NaCl}$ (200). From these results it is confirmed that the interaction between the substrate and $\mathrm{MgO}$ molecules becomes weak with $T_{\mathrm{S}}$ and then film grows epitaxially.

\section{4 The effect of annealing of deposited film} on the structure

The change of the preferred orientation and the crystallite size of the films subjected to the annealing was examined. Figure 6 shows the TED patterns and high resolution electron microscope (HREM) images obtained from the film (a) at $\delta=0^{\circ}, T_{\mathrm{s}}=\mathrm{R}$. T. and $P_{0_{2}}=1.0 \times 10^{-4}$ Torr deposited on collodion membrane and the films annealed for $30 \mathrm{~min}$ in air at (b) $500^{\circ} \mathrm{C}$ and (c) $1000^{\circ} \mathrm{C}$. The as-deposited film appeared to be a continuous sheet, the average crystallite size being about $5 \mathrm{~nm}$. The continuous rings of the TED patterns in Fig. 2 are attributed to these fine crystallites showing the (111) preferred orienta- 

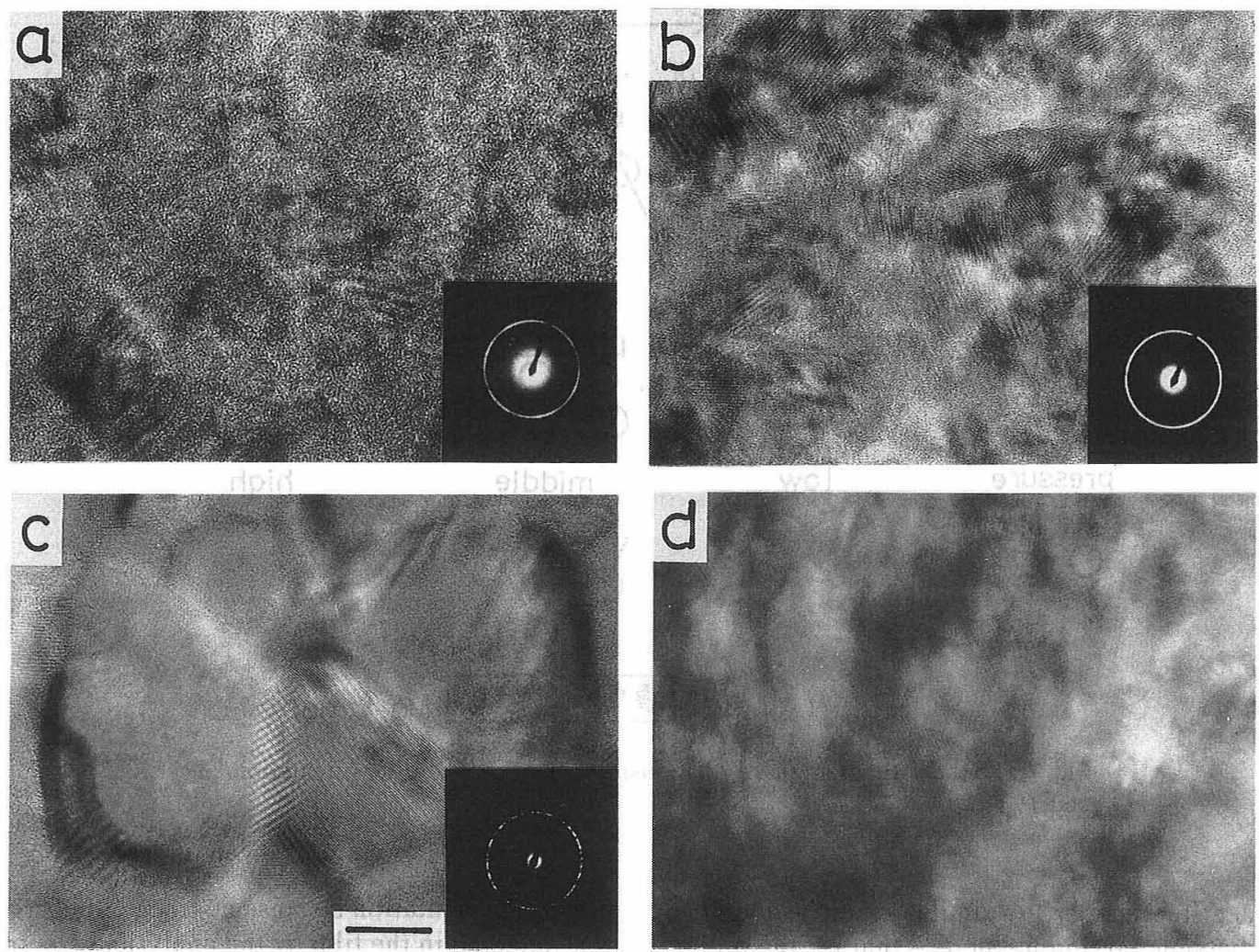

Fig. 6. HREM images and TED patterns of $\mathrm{MgO}$ film (a) deposited at $T_{\mathrm{s}}=\mathrm{R}$. T. , $P_{0_{2}}=1.0 \times 10^{-4} \mathrm{Torr}$ and $\delta$ $=60^{\circ}$, (b) annealed at $500^{\circ} \mathrm{C}$, (c) annealed at $1000^{\circ} \mathrm{C}$ for $30 \mathrm{~min}$ in air and (d) deposited on cleaved $\mathrm{NaCl}$ (200) at $300^{\circ} \mathrm{C}$. All micrographs in this figure are presented to the same magnification.

tion. The $500^{\circ} \mathrm{C}$ annealing did not cause any change in TED pattern. The HREM image showed that crystallite size did not change. However, Fig. 6 (c) shows the $1000^{\circ} \mathrm{C}$ annealing caused no change in crystallographic orientation but a change from a continuous ring to a discrete ring. This change of the ring shape arises from the growth of the crystallite up to $20 \mathrm{~nm}$ in size which is observed in the HREM image in Fig. 6 (c). The microstructure of the film annealed at $1000^{\circ} \mathrm{C}$ was different from the one deposited on cleaved $\mathrm{NaCl}(200)$ at $\delta=60^{\circ}, P_{\mathrm{O}_{2}}=1.0 \times$ $10^{-4}$ Torr and $T_{\mathrm{s}}=300^{\circ} \mathrm{C}$ (Fig. $6(\mathrm{~d})$ ).

\section{Discussion}

The (200) preferred orientation appeared in CVD or rf-sputtering $\mathrm{MgO}$ films has been explained by the Bravais's rule, ${ }^{1,7)}$ that is, the crystal orientation of a minimum energy configuration takes place. The (111) preferred orientation appeared in thermally evaporated films has been considered to be caused by the growth competition between differently oriented crystals. ${ }^{5)}$ The growth competition is due to the differences in the number of ions or molecules condensing on differently oriented crystals, For example, the condensation rate on $<111>$ oriented crystals is higher than that on $\langle 200\rangle$ oriented crystals when the ions or molecules arrive at the substrate at the rate of 130 $150 \mathrm{~nm} / \mathrm{min}^{5}{ }^{5}$

The (111) preferred orientation observed in the present experiment can be also explained by the growth competition scheme, judging from the resemblance of the $\delta$ dependence of the crystal orientation to its $P_{0_{2}}$ dependence. The (111) preferred orientation took place at a small $\delta$ and a high $P_{\mathrm{O}_{2}}$; both of which are connected with the low value of the arrival ratio of $\mathrm{Mg} / \mathrm{O}$ as shown in Fig. 7. The oxygen excess acts to the advantage of $\langle 111\rangle$ oriented crystallites in the growth competition through the following mechanism ; The creation ratio of crystalline nuclei with low surface free energy is larger than that of crystalline nuclei with high surface free energy as the magnesium particles energy lowers. The magnesium particles lose some of their excess energy by transferring it to the excess oxygen. $<111\rangle$ oriented crystallites develop in the growth competition as a (111) plane has minimum 


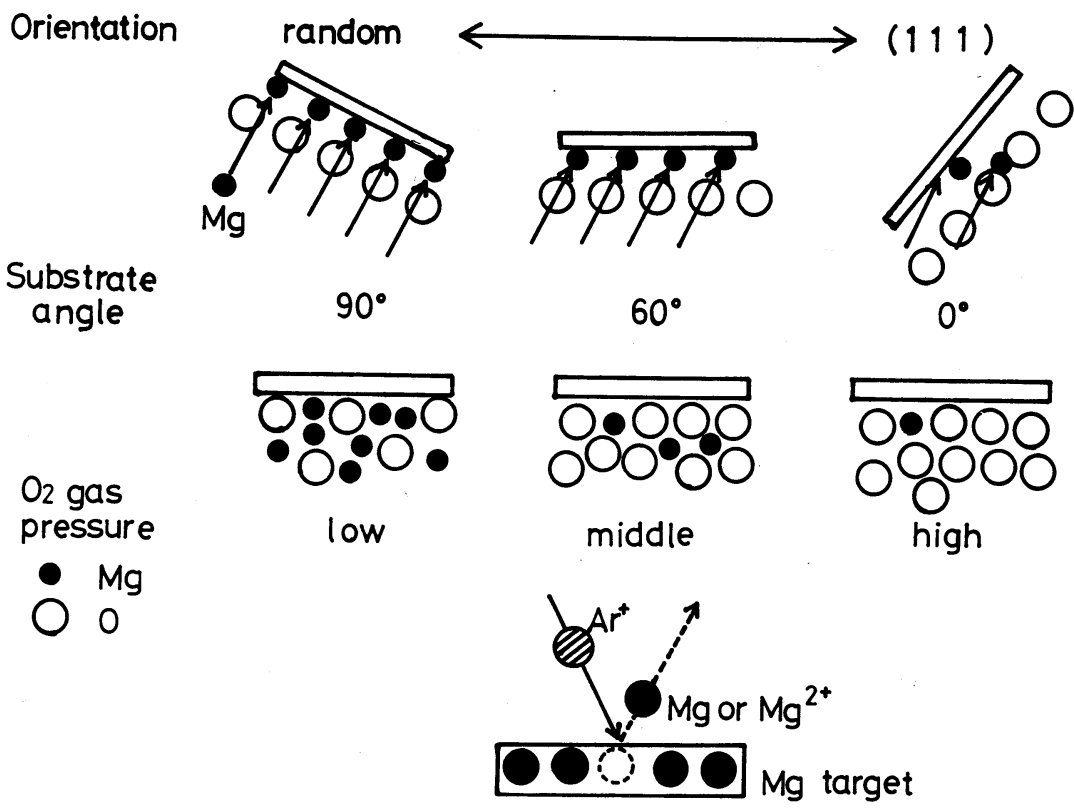

Fig. 7. Schematic diagram of retlationship between crystallite orientation, $\delta$ and $P_{\mathrm{O}_{2}}$.

surface free energy. A similar result is found in the dynamic mixing method, ${ }^{11}$ that is, the preferred orientation of TiN films is dependent on the arrival ratio, $\mathrm{Ti} / \mathrm{N}$ on the substrate. In their paper, it is considered that the variation of orientation arises from the variation of the energy deposition rate from the ion beam per a titanium atom. The energy deposition rate is determined by the arrival ratio. In this experiment, it is not clear whether the same energy deposition takes place in the low energy particles system. But, the change of preferred orientation with the arrival ratio resembles Sato's result. ${ }^{11}$

The small $\delta$ and high $P_{0_{2}}$ are also connected with the low deposition rate, the former through the geometrical $\sin \delta$ scheme and the latter throuth the low sputtering rate of the oxidized target surface. The low deposition rate may act to the advantage of $\langle 111\rangle$ oriented crystallites in the growth competition. But we don't think that the (111) preferred orientation arises only from the low deposition rate. If the (111) preferred orientation is caused by the low deposition rate, the size of crystallites should become large with decreasing the deposition rate. As shown in Fig. 6(a), however, all the films of the present experiment consisted of small crystallites regardless of both $\delta$ and $P_{0_{2}}$.

We deny the possibility that high energy species involved in this RIBSD process (such as energetic neutralized argons) might affect the preferred orientation because no trace of the argon was detected in the film by the analytical electron microscope.

\section{Conclusion}

The orientation of $\mathrm{MgO}$ films prepared by ion beam sputtering was strongly influenced by the substrate angle $(\delta), \mathrm{O}_{2}$ gas partial pressure $\left(P_{\mathrm{O}_{2}}\right)$ and the substrate temperature $\left(T_{\mathrm{s}}\right)$. As $\delta$ changed from $0^{\circ}$ to $90^{\circ}$, the TED pattern of the films changed from the (111) preferred orientation to a random orientation. As $P_{0_{2}}$ increased from $0.1 \times$ $10^{-4}$ to $10 \times 10^{-4}$ Torr, the TED pattern changed from a random orientation to the (111) preferred orientation. At $T_{\mathrm{s}}>100^{\circ} \mathrm{C}$, the TED pattern of the films on $\mathrm{NaCl}$ (200) showed epitaxial growth in contrast with a random orientation at $T_{\mathrm{S}}<$ $100^{\circ} \mathrm{C}$. Annealing below $500^{\circ} \mathrm{C}$ did not change the orientation and size of the crystallite. Annealing above $1000^{\circ} \mathrm{C}$, however, caused crystallite growth from $5 \mathrm{~nm}$ to $20 \mathrm{~nm}$ in size without any change in orientation. This size is still smaller than that of the crystallites deposited on a heated substrate. The $\mathrm{Mg} / \mathrm{O}$ ratio on the substrate at $T_{\mathrm{s}}$ $=\mathrm{R} . \mathrm{T}$. was considered to be the most important factor to affect the crystallographic orientation of the $\mathrm{MgO}$ thin film.

Acknowledgment The authors would like to thank Mr. K. Shibatomi of JEOL Ltd. for HREM observations. 


\section{References}

1) K. Kamata, Y. Shibata and Y. Kishi, J. Mater. Sci. Lett., 3, 423-26 (1984).

2) M. O. Aboelfotoh, J. Vac. Sci. Technol., 10, 621-25 (1973).

3) M. O. Aboelfotoh, Appl. Phys. Lett., 24, 347-49 (1974).

4) M. O. Aboelfotoh, J. Vac. Sci. Technol., 12, 67-70 (1975).

5) M. O. Abeolfotoh, K. C. Park and W.A. Pliskin, J. Appl. Phys., 48, 2910-17 (1977).

6) M. O. Aboelfotoh, J. Appl. Phys., 49, 2770-76 (1978).
7) K. Kamata, H. Hosono and T. Yamashita, Yogyo-KyokaiShi., 94, 910-12 (1986).

8) P. Vuoristo, T. Mantyla and P. Kettunen, J. Vac. Sci. Technol., A 4, 2932-36 (1986).

9) A. F. Hebard, A. T. Fiory, S. Nakahara and R. H. Erick, Appl. Phys. Lett., 48, 520-22 (1986).

10) M. Motoyama, K. Ishima, M. Kashihara and S. Koshiba, Appl. Surface Sci., 33/34, 567-77 (1988).

11) M. Sato, K. Fujii, M. Kiuchi and F. Fujimoto, Nuclear Instrument and Method in Physics Research., in press. 